\title{
Candida meningitis in suspected immunosuppressive patient - a case report
}

\author{
*E. O. Sanya', N. B. Ameen and B. A. Onile ${ }^{2}$ \\ *Department of Medicine and Medical Mirrohiology" \\ University of llorin Teaching Hospital \\ P.M.B. 1459, Ilorin, \\ Kwara State, Nigeria \\ E-mail tundesanya@hotmail.com
}

\begin{abstract}
Summary
Meningitis due to fungal agents represents an AIDS defining event and occurs typically with very low CD4+ lymphocyte count. Candida meningitis is still a rare clinical condition, although it is becoming frequently reported in the background of immune suppressive states such as: drug addicts, cancer patients, organ transplant recipients and HIV/AIISS patients. In this report we highlight a case of candida meningitis, in a 25-year old female patient. She presented with vulva swelling, vaginal discharge and fever, with rapid progression to tonic-clonic convulsions and loss of consciousness. She fully recovered after treatinent with fluconazole.
\end{abstract}

Key-words: Candida albicans - MeningitisImmunosuppression-HIV-Opportunistic

\section{Résumé}

Méningite provoquée par des agents de la mycose constitué un évenement qui détermine le IDA et arrive typiquement avec un niveau du CD4t compte de lymphocyte très bas. Méningite candida demeure toujours une condition clinique très rare, quoique elle soil rapportée fréquemment dans le debut d'état d'immuno suppressif tel que: toxicomane, cancereux, receveurs, et patients séropositifs. Dans cette étude, nous soulignos un cas de la méningite candida chez une patiente du sexe féminin âgée de 25 ans. Elle s'est présentée atteinte du gonflement de la vulve, pertes blanches, et la fièvre avec une progression rapide à la convulsion tonique-clonique el perte de la conscience. Elle était tout à fait remis après la prise en charge avec fluconazole.

\section{Introduction}

In the Sub-Saharan Africa more than 30 million people are suspected to be living with HIV/AIDS '. People with advanced HIV infection are vulnerable to infections or malignancies that are called "opportunistic infections" because they take advantage of the opportunity offered by a weakened immune system ${ }^{2,3,4,5}$.

Opportunistic infections result in significant morbidity and mortality for people living with HIV/AIOS. one of which is meningitis: ". Meningitis means inflammutis of of the meninges, which are the membranes covering the brain and the spinal cord'.

Meningitis in immunocompromised state may not present with the typical clinical features as seen in the general population ${ }^{6.8}$. One meta-analysis reported stiff neck in $50 \%$ of cases of non- AIDS meningitis and in $22 \%, 31 \%, 37 \%$, and $44 \%$ of cases of meningitis in AIDS patients in four different studies 9

Many people have been exposed to fungal infections at some time during theix lives, but the immune system usually stops the fungi from causing illness. When HIV infection weakers the immune system, then fungi could cause illness. Cryptococosis is the most common systemic fungal infection associated with HIV/AIDS, and the most frequent illness caused by this fungus is cryptococcal meningitis ${ }^{9,10}$. Other fungal infections of the central nervous system, though rare, are presently being reported worldwide $11 \cdot 13$. We report here a case of candida meningitis that initially did not respond to antibiotics. The diagnosis of systemic candidosis was made as a result of profuse growth of the fungi in cultured specimen of urine and vaginal discharge. Subsequent commencement of oral fluconazole resulted in marked improvement in patient's clinical condition.

\section{Case report}

Miss OOM, was an unmarried hairdresser who presented to the maternity wing of the University of Ilorin Teaching Hospital with a 3 -day history of fever and left vulval swelling followed by generalized tonic-clonic seizures of 2 days duration. The fever was low grade, intermittent with no chills and rigor. The vulval swelling was intensely painful and later ruptured spontaneously. On the day of presentation, the patient developed generalized tonic-clonic seizures that were not preceded by aura, and associated with sphincteric impairment. After the initial convulsion the patient became unconscious. Within a space of 6 hours, she had experienced up to six episodes of generalized tonic-clonic convulsions, each lasting between 15-20 minutes. Patient was not a known epileptic and there was no family history of epilepsy. She was not on any immune suppressing medication.

Patient had been noticed to be losing weight about 8 months before presentation with on-and-off palsiage of loose stoml that was neither mucoid nor blond sained.

\section{*Correspondence}


She had a similar vulval swelling three and half months earlier, which resolved spontaneously. She gave a history of multiple sexual partners and had procured an abortion 3 years earlier. Patient subsequently had another pregnancy, which though she carried to term but the baby died three days after delivery from an unknown ailment. She was pale and febrile to touch (temperature of $39 .{ }^{\circ} \mathrm{C}$ ). There was submandibular lymph nodes enlargement and was unconscious with Glasgow coma score of $3 / 15$. The peripheral pulse rate was 122 beats per minute and her blood pressure was $130 / 100 \mathrm{mmHg}$. Significant neurologic findings were: neck stiffness, positive Kernig's and Brudzinski's signs. There was generalized muscle hypotonia with depressed deep tendon reflexes, and mild pupillary dilatation, which reacted sluggishly to light. There was suprapubic tenderness with purulent white vaginal discharges. Other systernic examination findings were unremarkable. The impression at presentation was meningitis with Bartholin's abscess in a suspected HIV infected patient.

The packed cell volume was $21 \%$, total WBC was 10,000/cc (differentials of Neutrophils-68\%, Lymphocytes$22 \%$, and Eosinophils $10 \%$ ), with toxic granulations and ESR of $69 \mathrm{mmHr}$. No malaria parasite was seen on blood film. Random blood sugar was $6.0 \mathrm{mmol} / \mathrm{dl}$. The serum biochemical results were within normal limits. Urine microscopy, culture and sensitivity came out with a profuse growth of Candida albicans with numerous WBC. Blood culture grew no organism. Culture of vaginal swab gave a moderate growth of Candida albicans while the microscopy showed scanty pus and yeast cells. Results of CSF culture on Saboraud's agar grew the same organism with WBC of 16/HPF and RBC 8,480/HPF. Patient was unable to carry out screening test for HIV infection due to financial constraint amongst other reasons. She was empirically started on triple antimicrobial agents including intravenous Metronidazole $500 \mathrm{mg}$ every 8 hours, and Ciprofloxacin $400 \mathrm{mg} 12$ hourly that was subsequently changed to Ceftriazone $1 \mathrm{gm}$ 12 hourly for 72 hours with no appreciable improvement. After obtaining the laboratory results she was commenced on oral fluconazole $200 \mathrm{mg} 12$ hourly (since relative could not afford the cost of intravenous infusion) and nystatin vaginal pessaries 2 tablets twice daily. After the $3^{\text {rd }}$ day, patients showed marked clinical improvement, became afebrile, Glasgow coma score rose to $13 / 15$ with complete cessation of seizures. Due to a marked improvement in patient's clinical condition, she discharged herself after 15 days of admission and has since been lost to follow up and further assessment.

Specific treatment with antiretroviral agents could not be instituted in this patient because of the prohibitive cost of these medications as of the time of her admission. Even the HIV status and the CD4+ counts were yet to be determined, her clinical condition was supportive of a likelihood of HIV/AIISS.

\section{Discussion}

Systemic fungal infection in the background of immunosuppression is common ${ }^{4,13.14}$, and in some instances herald clinical manifestation of AIDS 15 . Under depressed immunity, fungal meningitis may present with absence of the classical symptoms of meningitis or meningoencephalitis different from the general population. The CSF may also show little or no abnormalities with respect to cells, protein and glucose content". Therefore a high index of suspicion is necessary to make the diagnosis of fungal meningitis. Recently, a case of Scopularopsis meningitis was reported at our center ${ }^{11}$.

In the case highlighted here, there were evidences of vaginal candidosis and urinary tract infection. Although the lumbar puncture was traumatic, the CSF and urine cultures grew Candida albicans. Due to financial constraint, HIV screening test could not be done. However, clinical presentation raised a high possibility of HIV infection. Serum glucose excluded diabetes mellitus.

Cryptococca meningitis is the most frequent systemic fungal infection in HIV-infected persons ${ }^{14}$. It occurs in about $5.7 \%$ of AIDS patients in USA with mortality close to $20 \%$. Without treatment, life expectancy is probably less than a month ${ }^{\circ}$.

Meningitis due to Candida species is not so common, and the most frequent isolate is Candida albicans in about $54 \% .65 \%$ of cases $9,16,17$. Others include $C$. parapsilosis $-23 \%$, C tropicalis-15\%,C krusei $-8 \% 17$. Meningitis due to Candida albicans is a rare disease that is seen mostly in neonates, neurosurgical patients, and cancer patients as well as in other immunocompromised states ${ }^{3-5,16,18}$. There are 2 main types of candidiasis in HIV patients (of the mouth and throat, as well as the vagina) and systemic disease (of the esophagus, and disseminated disease). The mouth and throat variant (oropharyngeal candidiasis or OPC) is believed to occur at least once in the lifetime of all HIVinfected patients. While OPC is not a cause of death, it causes oral pain and makes swallowing difficult. The occurrence of candida meningitis in this patient, although her HIV status is unknown, supports a clinical diagnosis of HIV/AIDS since meningitis due to fungal agents represents an AIDS-defining event which occurs typically with very low $\mathrm{CD} 4+$ lymphocyte counts ${ }^{9}$. The response of our patient to oral fluconazole (200mg twice daily), a first line new triazole antifungal drug is not surprising. Fluconazole has been shown to have the best pharmacokinetic profile and with the least incidence of adverse effects among all the systemic antifungal agents available today ${ }^{15,19-22}$. Therefore in HIV patients with meningitis but where the CSF picture does not support a bacterial eriology, fungal infection should be considered a possibility where this organism is isolated from a secondary site. 


\section{References}

1. HIV/AIDS Surveillance (UNAIDS) reports, 1999: (No2):1;2000.

2. John MA, Coovadia Y.Meningitis due to a combined infection with Cryptococcus neoformans and Streptococcus pneumoniae in an AIDS patient. J Infect. 1998 Mar;36:231-2.

3. JA McCullers, SL Vargas, PM Flynn, BI Razzouk, JL Shenep. Candidal Meningitis in Children with Cancer. Clinical Infectious Diseases 2000;31:451-457.

4. Krupova Y, Sejnova D, Dzatkova J, et al. Prospective study on fungemia in children with cancer: analysis of 35 cases and comparison with 130 fungemias in aduits. Support Care Cancer 2000;8:427-30.

5. Ralph ED, Hussain Z. Chronic meningitis caused by Candida albicans in a liver transplant recipient: usefulness of the polymerase chain reaction for diagnosis and for monitoring treatment. Clin Infect Dis. 1996; 23:191-2.

6. Powderly WG. Cryptococcal meningitis and acquired immunodeficiency syndrome. Clin Infect Dis 1993; 17:837-42.

7. Maurice Victor and Allan H Ropper. Viral infections of the nervous systems and Prion diseases. In. Adams and Victor's (ed) Principles of Neurology. Mc Graw-Hill $7^{\text {th }}$ Ed. International edition. Pg783-820.

8. Casado JL, Quereda C, Oliva J, Navas E, Moreno A, Pintado V, Cobo $\mathrm{J}$, Corral 1. Candidal meningitis in HIVinfected patients: analysis of 14 cases. Clin Infect Dis 1997; 25:673-6.

9. Thomas FP. HIV -1 associated CNS condition: Meningitis. emedicine; $1-10$.

10. Steven LC and Merle AS. Infections with Cryptococcus neoformanse in patients with acquired immunodeficiency syndrome. N Engl J Med 1989; 321:794-99.

11. C, Nwabuisi; AK, Salami; NA Abdullahi and OO Agbede. Scopulariosis associated meningitis in adult Nigerian AIDS patient-A case report. WAJM 2003; 22:364-5.
12. Tiberghien F, De Seze J, Stojkovic 'T et al. Candida albicans meningoencephalomyeloradiculitis. Rev Neurol (Paris) 2002; 158:473-6.

13. Anaisse E. Opportunistic mycoses in the immunocompromised host: Experience at a cancer center and review. Clin Infect Dis 1992;14 (suppl 1)543-.53.

14. Muyembe Tamfum IJ, Mupapa Kibadi D, Nganda L, Ngwala-Bikindu D, Kuezina T, Kela-We I, Vandepitte J. Cryptococcosis caused by Cryptococcus neoformans var. Gattii. A case associated with Acquired Irmmunodeficiency Syndrome (AIDS) in Kinshasa, Zaire. Med Trop (Mars). 1992; 52:435-8.

15. Bruinsma-Adams IK. AIDS presenting as Candida albicans meningitis: a case report. AIDS.1991; 5:12689.

16. Chen TL, Chen HP, Fung CP, Lin MY, Yu KW, Liu CY. Clinical characteristics, treatment and prognostic factors of candidal meningitis in a teaching hospital in Taiwan. Scand J Infect Dis. 2004; 36:124-30.

17. Dorko E, Pilipcinec E, Tkacikova L Candida species isolated from cerebrospinal fluid.Folia Microbiol (Praha). $2002 ; 47: 179.81$.

18. Aleixo MJ, Caldeira L, Ferreira ML. Candida albicans meningitis: clinical case. J Infect. 2000; 40:191-2.

19. Yonga G. Current drug therapy of systemic mycoses: a review. East Afr Med J. 1995; 72:394-8.

20. Rodriguez-Arrondo F, Aguirrebengoa K, De Arce A et al. Candidal meningitis in HYV-infected patients: treatment with fluconazole. Scand J Infect Dis. 1998; 30:417-8.

21. Troke PF. Large-scale multicentre study of fluconazole in the treatment of hospitalised patients with fungal infections. Multicentre European Study Group. Eur J Clin Microbiol Infect Dis. 1997; 16:287-95.

22. AE Brouwer, A Rajanuwong, W Chierakul, GE Griffin, RA Larsen, NJ White, TS Harrison. Combination antifungal therapies for HIV-associated cryptococcal meningitis: a randomised trial. The lancet. 2004;(363). 1764-1767. 